\title{
EL VASO CARENADO DE BEXO (DODRO, A CORUÑA)*
}

\author{
M. Pilar Prieto Martínez \\ Universidad de Santiago de Compostela \\ ORCID iD: http://orcid.org/0000-0002-5152-630 \\ Pablo VÁzQuez Liz \\ Universidad de Santiago de Compostela \\ ORCID iD: http://orcid.org/0000-0002-6088-5774 \\ Vicente Caramés Moreira \\ Museo del Mar de Galicia \\ ORCID iD: http://orcid.org/0000-0002-4451-2337
}

\begin{abstract}
* Este trabajo ha sido desarrollado en el marco de 2 proyectos: "Estudio del cambio social en el III y II milenios BC en el NW de la Península Ibérica a partir de yacimientos de contexto mixto" (HAR2012-34029). Programa Nacional de Proyectos de Investigación Fundamental, Ministerio de Economía y Competitividad, entre 2013 y 2015. "Tecnología y producción de la cerámica medieval de Galicia" (MC-PTG). HAR2015-64441-P (Plan Nacional: Ministerio de Economía y Competitividad, Convocatorias 2015, Proyectos EXCELENCIA y Proyectos RETOS, Dirección General de Investigación Científica y Técnica, Subdirección General de Proyectos de Investigación), 2016-2019. Agradecemos la posibilidad de estudiar el vaso al Museo del Mar de Galicia, asimismo agradecemos al Museo Arqueológico Provincial de Ourense el permiso para tomar fotografías de las vasijas de Pardolláns y Partovia de las figuras 5 y 6 y al Museo Arqueológico Provincial de Pontevedra el permiso para tomar fotografías de la vasija Marco de Camballón en la figura 5.
\end{abstract}

Copyright: C 2018 CSIC. La edición electrónica de esta revista se distribuye bajo los términos de una licencia de uso y distribución Creative Commons Reconocimiento 4.0 Internacional (CC BY 4.0).

Cómo citar/Citation: M. Pilar Prieto Martínez, Pablo Vázquez Liz y Vicente Caramés MoreiRA, "El vaso carenado de Bexo (Dodro, A Coruña)", Cuadernos de Estudios Gallegos, 65, núm. 131 (2018), págs. 13-35, https://doi.org/10.3989/ceg.2018.131.01 


\section{EL VASO CARENADO DE BEXO (DODRO, A CORUÑA)}

\section{RESUMEN}

Se presenta un recipiente carenado profusamente decorado recuperado durante las labores de la draga de la desembocadura del río Ulla. Se tratarán las condiciones de su hallazgo, se realizará una caracterización formal de la pieza y dado que sus rasgos, a primera vista, no son representativos de la cerámica prehistórica de la zona, se buscarán paralelos que permitan encuadrar una cronología relativa para el mismo, probablemente de la segunda mitad del II milenio a.C.

Palabras Clave: Edad del Bronce, Galicia, Vasos carenados, Río Ulla.

\section{O VASO CARENADO DE BEXO (DODRO, A CORUÑA)}

\section{Resumo}

Preséntase un recipiente carenado profusamente decorado recuperado durante os labores da draga da desembocadura do río Ulla. Trataranse as condicións do seu achado, realizarase unha caracterización formal da peza e dado que os seus trazos, a primeira vista, non son representativos da cerámica prehistórica da zona, buscaranse paralelos que permitan encadralo nunha cronoloxía relativa, probablemente da segunda metade do II milenio a.C.

Palabras Clave: Idade do Bronce, Galicia, Vasos carenados, Río Ulla.

\section{THE CARINATED VESSEL FROM BEXO (DODRO, A CORUÑA)}

\section{AbStract}

In this article we will present a profusely decorated carinated vessel recovered during the dredging works at the mouth of the Ulla river. The conditions of its discovery will be treated and a formal characterization of the piece will be done. As its features are not representative of the prehistoric ceramics of the area, parallels will be sought to get a relative chronology. The conclusions link the vessel probably to the second half of the second millennium BC. KeY words: Bronze Age, Galicia, Carinated vessels, Ulla river, 
1 objetivo del presente trabajo es dar a conocer una pieza única en el registro arqueológico gallego, un vaso carenado encontrado en Bexo (Dodro, A Coruña). Este recipiente fue hallado completo y posee unas características particulares y únicas en la región, pero desgraciadamente, no se dispone de información contextual del hallazgo. Creemos necesario publicarlo intentando valorar una cronología relativa para el mismo a partir de la búsqueda de paralelos que nos permitan encuadrarlo, al menos a grandes rasgos, en un grupo cultural.

Partimos de la base de que la comparación en arqueología es un método que continúa estando vigente y siendo muy útil para poder establecer una aproximación no sólo formal sino también cronológica a piezas que aparentemente no parecen tener nada en común con el registro arqueológico de una zona dada. Si bien somos conscientes de las carencias que esta metodología también acarrea, es indudable que es un punto de partida básico que permitirá realizar una primera interpretación, por lo tanto, ésta es la única aproximación disponible por el momento para conseguir ir más allá de la pieza.

\section{LOCALIZACIÓN Y ENTORNO ARQUEOLÓGICO DEL VASO}

Existen dificultades para concretar la localización exacta del hallazgo del vaso, ya que es una pieza encontrada de forma casual. El vaso se localizó a finales de los 70 o principios de los 80 del siglo XX, en un dragado de la margen derecha del río Ulla, en las inmediaciones de la Illa de Bexo/As Brañas, concretamente en las proximidades de la confluencia del rego dos Campelos en aquel.

El área del río Ulla, y en particular su desembocadura, es especialmente rica en yacimientos arqueológicos de diferentes épocas (fig. 1) ${ }^{1}$, habiendo sido recu-

\footnotetext{
1 Los yacimientos han sido localizados en el mapa a partir de tres trabajos. Los túmulos del Barbanza han sido ubicados a partir de Víctor José Barbeito Pose, Ramón FÁbregas Valcarce, Carlos RodrígueZ Rellán, Ramón Blanco Chao, Manuela Costa-Casais, María Martín SeiJo, Alexandre Paz Camaño, Alfonso FariÑa Costa y Lino Gorgoso López, “Ocupacións domésticas na serra do Barbanza: resultados preliminares”, Gallaecia, 34 (2015), fig. 2, pág. 128. La localización de los túmulos del área de Vilagarcía de Arousa han sido tomados de Félix GonzÁlez ÍnsuA, "Aproximación a la distribución espacial de sitios
} 
perados objetos realizados en diversos materiales, principalmente cerámicos y metálicos.

Las síntesis existentes de la zona dejan ver esta riqueza ${ }^{2}$, con una docena de pecios posibles localizados, entre los que destaca el romano de Cortegada, junto a los bien conocidos núcleos romanos de Iria Flavia y Pontecesures en los que fueron encontrados restos de una estructura portuaria y un pequeño barco de madera de los que no se han podido concretar la cronología. Asimismo, son conocidas fortalezas medievales como las de Torres de Oeste, emplazadas sobre un castro. También han sido recuperados abundantísimos materiales cerámicos pertenecientes a ánforas romanas y a cerámicas medievales.

Pero el área presenta una especial densidad de piezas metálicas de la Edad del Bronce. Entre los objetos metálicos de esta época destacan principalmente armas tales como un estoque y un puñal Rosnöen, dos hachas de talón y dos anillas, una punta de lanza flameante, cuatro espadas pistiliformes dos de ellas evolucionadas, una espada tipo Sa Idda evolucionada, un puñal lengua de carpa, 43 hachas de talón y dos anillas enterradas en la orilla del río en Monte de O Porto. Además de armas se ha documentado el famoso tesoro del casco de Leiro en oro en la zona de Rianxo. La presencia de las referidas armas en el cauce Ulla puede estar relacionada con prácticas cultuales (deposición intencional) o funerarias (ofrendas o ajuares) vinculadas a los cursos fluviales o medios acuáticos, bien documentadas en otras zonas de la fachada atlántica ${ }^{3}$.

La ría de Arousa es muy rica en restos arqueológicos, y en la medida que se intensifican los trabajos arqueológicos en la zona, se va recuperando mayor información que está permitiendo conocer mejor la región, como es el caso por ejemplo del islote de Guidoiro Areoso ${ }^{4}$ donde los trabajos de prospección y

arqueológicos de la Prehistoria Reciente en la Ría de Arousa (Pontevedra)”, Gallaecia, 32 (2013), fig. 3, pág. 137. El resto de los yacimientos han sido tomados del trabajo de David Fernández Abella, "El río Ulla: primeras investigaciones en la ruta fluvial al corazón de Galicia a la luz de la convención de la UNESCO”, en J. Cascalheira y C. Gonçalves (eds.), JIA 2011, IV Jornadas de Jovens em Investigação Arqueológica. Promontoria monográfica, 16, vol. II, 2012, figs. 2 y 3, pág. 110.

2 Juan L. Naveiro López, El comercio antiguo en el NW peninsular, A Coruña, Edicións do Museo Arqueológico e Histórico, 1991; Félix GonzÁlez ÍNSUA, “Aproximación a la...”, págs. 129-167; Víctor José Barbeito Pose, Ramón Fábregas Valcarce, Carlos Rodríguez Rellán, Ramón Blanco Chao, Manuela Costa-Casais, María Martín Seijo, Alexandre Paz Camaño, Alfonso Fariña Costa y Lino Gorgoso López, “Ocupacións domésticas...”, págs. 125-158; D. Fernández Abella, "El río Ulla...” págs. 107-117.

3 Ramón FÁBregas Valcarce y Richard Bradley, "El silencio de las fuentes: prácticas funerarias en la edad del Bronce del noroeste y su contexto europeo”, Complutum, 6 (1995), págs. 160, 162-163. Gonzalo Meijide Cameselle, "El concepto de las relaciones atlánticas en la Edad del Bronce del Noroeste", en Ladislao Castro Pérez y Susana Reboreda Murillo (coord.), Edad del Bronce, Xinzo de Limia, Excmo. Concello de Xinzo de Limia, 1994, págs. 217-218.

4 Elías López-Romero, Alejandro Güimil-Fariña, Patricia Mañana-Borrazás, Carlos Otero Vilariño, M. Pilar Prieto Martínez, José Manuel Rey García y Xosé Ignacio Vilaseco Vázquez, “Ocupación humana y monumentalidad durante la Prehistoria Reciente en el islote de Guidoiro Areoso (Ría de Arousa, 


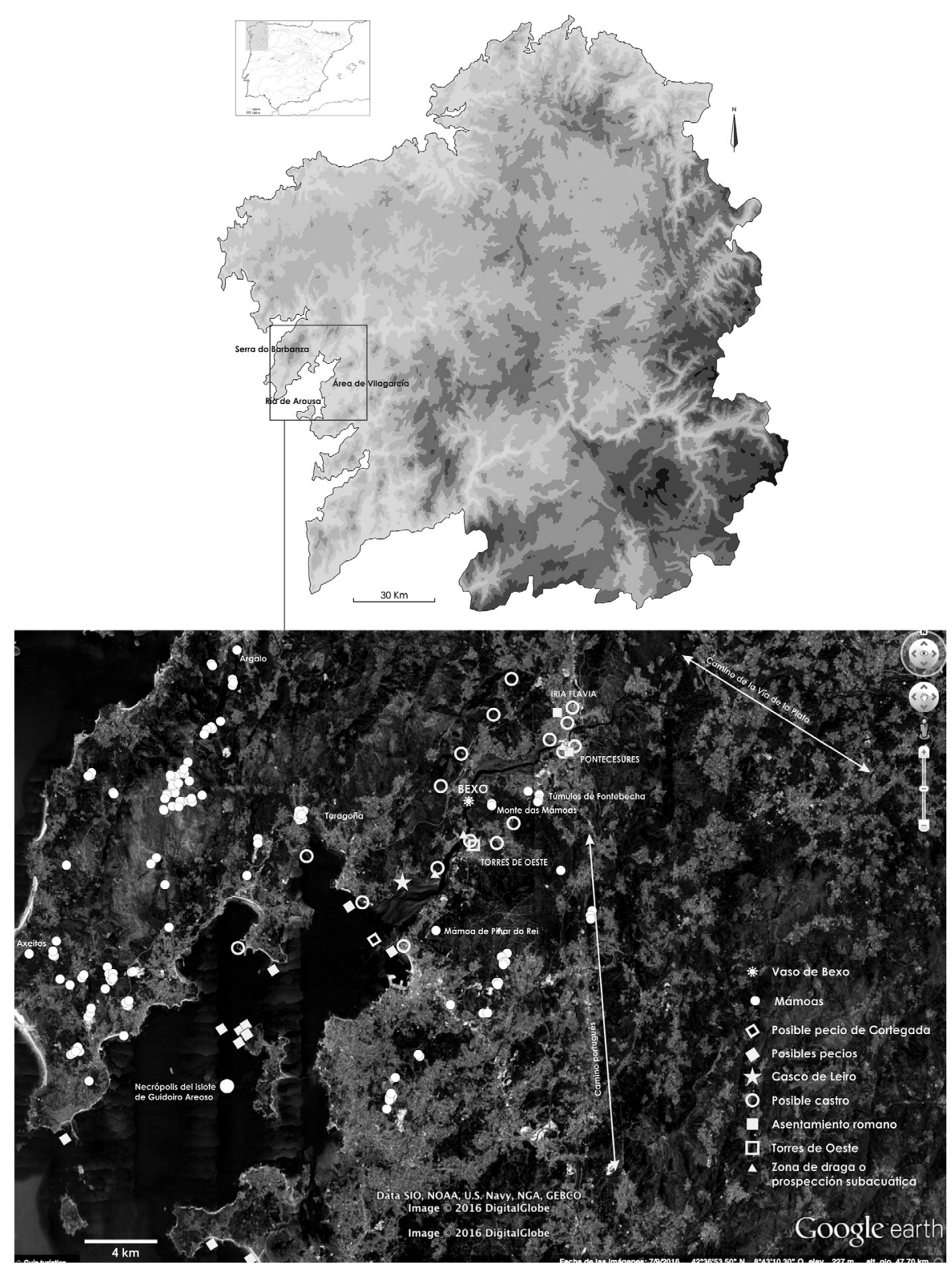

Fig. 1. Localización del yacimiento y entorno. 
excavación están permitiendo definir una etapa más prolongada e intensa de lo que se conocía anteriormente. Otros trabajos recientes de mayor escala territorial completan el conocimiento arqueológico de la Ría de Arousa tanto en su orilla sur $^{5}$ como en la norte ${ }^{6}$ mostrando la gran riqueza de la comarca desde antiguo, entre los que destacan docenas de túmulos, como hemos señalado en el mapa de la fig. 1. Dentro de este conjunto de hallazgos, por lo tanto, consideramos de interés destacar el vaso carenado de Bexo inédito y depositado en el Museo del Mar de Galicia en la actualidad.

\section{CARACTERIZACiÓN DEL VASO CARENADO}

En este apartado describiremos de la forma más detallada posible las características del vaso para poder reconstruir, al menos parcialmente, su cadena operativa. Así, realizaremos una descripción de sus rasgos morfológicos, técnicos y decorativos (figs. 2 y 3 ).

En relación con los rasgos morfológicos y métricos del vaso (Tabla 1), cabe destacar que se conserva completo, estas condiciones de conservación son realmente excepcionales y habitualmente son encontradas en contextos cerrados como enterramientos. El vaso está hecho a mano y tiene un ancho grosor de pared oscilando entre los 8 y $11 \mathrm{~mm}$ a lo largo del perfil y sufriendo un ensanchamiento en el labio y la carena de $20 \mathrm{~mm}$. Su morfología es compuesta abierta, dado que el diámetro de su boca es ligeramente mayor que el de cualquier otra parte del recipiente. Su perfil muestra una carena media-baja y un cuello muy estrangulado y esbelto que remata en un borde plano engrosado. El fondo es convexo finalizando en un pequeño umbo, que sirve como superficie sobre la que el recipiente se puede apoyar para sostenerse erguido. Asimismo, el diámetro de su boca es mayor que su altura resultando una forma achaparrada. Su capacidad es de casi litro y medio, por lo que se puede considerar un recipiente de pequeñas dimensiones, con una función probablemente asociada a contener algún tipo de líquido o semilíquido de forma puntual como vajilla de servicio.

Además de su perfil, es interesante pararse un momento en los elementos de prehensión. El vaso presenta un asa en cuyo hueco podrían ser introducidos dos dedos para sostener el vaso correctamente, por lo que se podría pensar que fue sujetada de dicha forma, cuyo arranque superior se une al borde y el inferior

\footnotetext{
Pontevedra). Investigaciones en el marco de las dinámicas litorales atlánticas actuales", Trabajos de Prehistoria, 72 (2) (2015), págs. 353-371.

5 Félix GonzÁlez ÍnsuA, “Aproximación a la...”, págs. 129-167.

6 Víctor José Barbeito Pose, Ramón Fábregas Valcarce, Carlos Rodríguez Rellán, Ramón Blanco Chao, Manuela Costa-Casais, María Martín Seijo, Alexandre Paz Camaño, Alfonso Fariña Costa y Lino Gorgoso LóPEZ, “Ocupacións domésticas...”, págs. 125-158.
} 
Tabla 1. Dimensiones de la pieza en milímetros

\begin{tabular}{|c|c|c|c|c|c|c|c|}
\hline BOCA Ø & $\begin{array}{l}\text { ANCHURA } \\
\text { DEL BORDE }\end{array}$ & Cuello Ø & CARENa $\varnothing$ & Uмво Ø & Altura & $\begin{array}{l}\text { GROSOR } \\
\text { PAREDES }\end{array}$ & $\begin{array}{c}\text { CAPACIDAD } \\
\left(\mathrm{CM}^{3}\right)\end{array}$ \\
\hline 166 & 20 & 130 & 156 & 23 & 155 & $\begin{array}{c}8-11 \mathrm{~mm} \\
20 \mathrm{~mm} \text { en carena }\end{array}$ & 1400 \\
\hline
\end{tabular}

se apoya sobre la carena. Su perfil en cinta ancha se ensancha mucho hacia los extremos, la parte superior e inferior, respecto a su zona central, recordando a algunos $\mathrm{LBH}^{7}$.

En relación con el tratamiento de las pastas, se observa un acabado alisado medio. La pieza no pudo ser observada en fractura por estar completa y no disponer de partes desconchadas que permitieran la observación del corte de sus paredes, por lo cual tampoco podemos conocer las características de los desgrasantes en fractura, ni su coloración, información interesante asociada a la fase de tratamiento de la materia prima en fase de premodelado y fase de cocción, respectivamente. Así que únicamente disponemos de la información que hemos podido obtener de la superficie exterior. Esta superficie más bien de tonos naranjas permite pensar que, al menos, en los momentos finales de su cocción el ambiente fue oxidante. Las texturas son compactas medias, con desgrasantes micáceos y cuarcíticos, que en algún caso alcanzan los $3 \mathrm{~mm}$ de tamaño, aunque en general son más pequeños, abundantes y están distribuidos de manera irregular por la superficie.

El estado de conservación de la pieza es relativamente bueno ya que no presenta desconchados de gran tamaño ni abundantes (sólo un ligero desgaste superficial en el asa que ha borrado una parte de la decoración), si bien la superficie exterior posee en la base trazas de carbonatos secundarios, que se forman habitualmente en ambientes húmedos por exceso de agua o encharcamiento, asimismo posee una costra oscura en la base y un lateral que podría ser indicativo de la zona en la que el vaso quedó apoyado desde su deposición hasta el momento de su recuperación.

Finalmente, si nos centramos en la decoración podemos tratar tanto las técnicas como los diseños y el esquema decorativos. En lo que atañe a las técnicas decorativas, se aplica una incisión fina e impresión profunda de punzón con forma en planta circular, resultado de la aplicación del punzón de forma tranversal a la pared de la vasija (cuya punta es de un diámetro de $2 \mathrm{~mm}$ ) y ovalada, aplicando el punzón de forma lateral ( $5 \mathrm{~mm}$ x $3 \mathrm{~mm}$ ). Los elementos decorativos son simples y de gran tamaño, a base de líneas horizontales rectilíneas que se suceden verticalmente, aunque trazadas de forma descuidada e irregular.

\footnotetext{
Ver Laure Nonat, Pablo Vázquez Liz y M. Pilar Prieto Martínez, El Vaso de Largo Bordo Horizontal. Un trazador Cultural del Noroeste de la Península Ibérica en el II Milenio BC, Oxford, Archaeopress BAR Internacional Series 2699, 2015.
} 
La organización espacial de la decoración es horizontal en cenefa, realizada a base de líneas horizontales incisas e impresas que se van alternando en sentido vertical, de arriba hacia abajo. El diseño ocupa la mitad superior de la vasija, utilizando la carena como límite inferior del mismo. El labio presenta líneas incisas. Si se observa desde arriba, la boca ancha y decorada del vaso de Bexo recuerda un LBH (largo bordo horizontal), sin embargo, observando su perfil, esta forma es descartada.

El recipiente tiene una apariencia final buena pero no extremadamente cuidada como puede ser documentada en otras vasijas prehistóricas, como algunos campaniformes, sin embargo, su calidad parece buena, como hemos visto a través de las características de sus pastas o la precisión de su morfología, quizás la decoración es la parte realizada con menos preocupación.

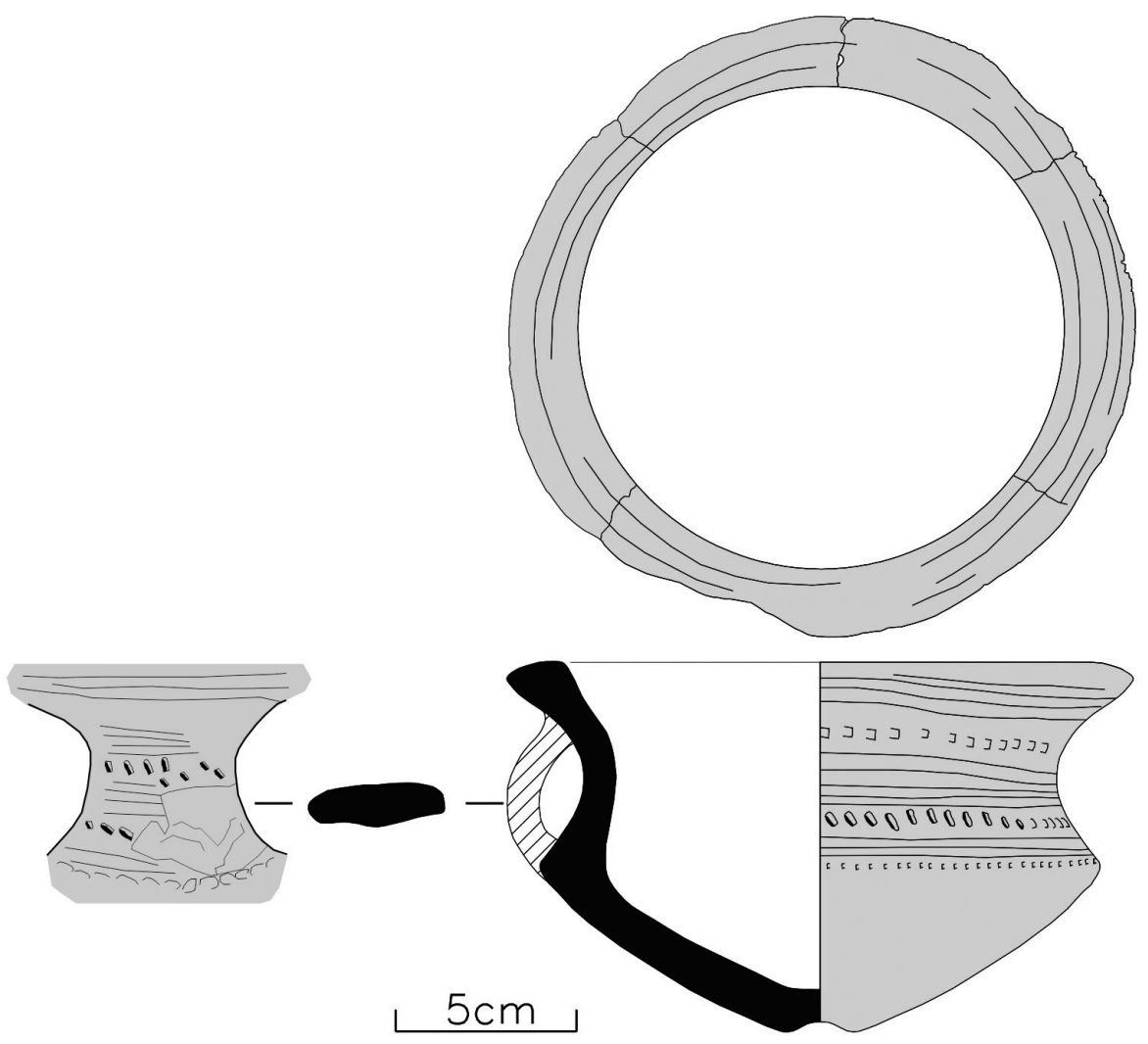

Fig. 2. Dibujo del vaso (diseño de MPPM y PVL). 

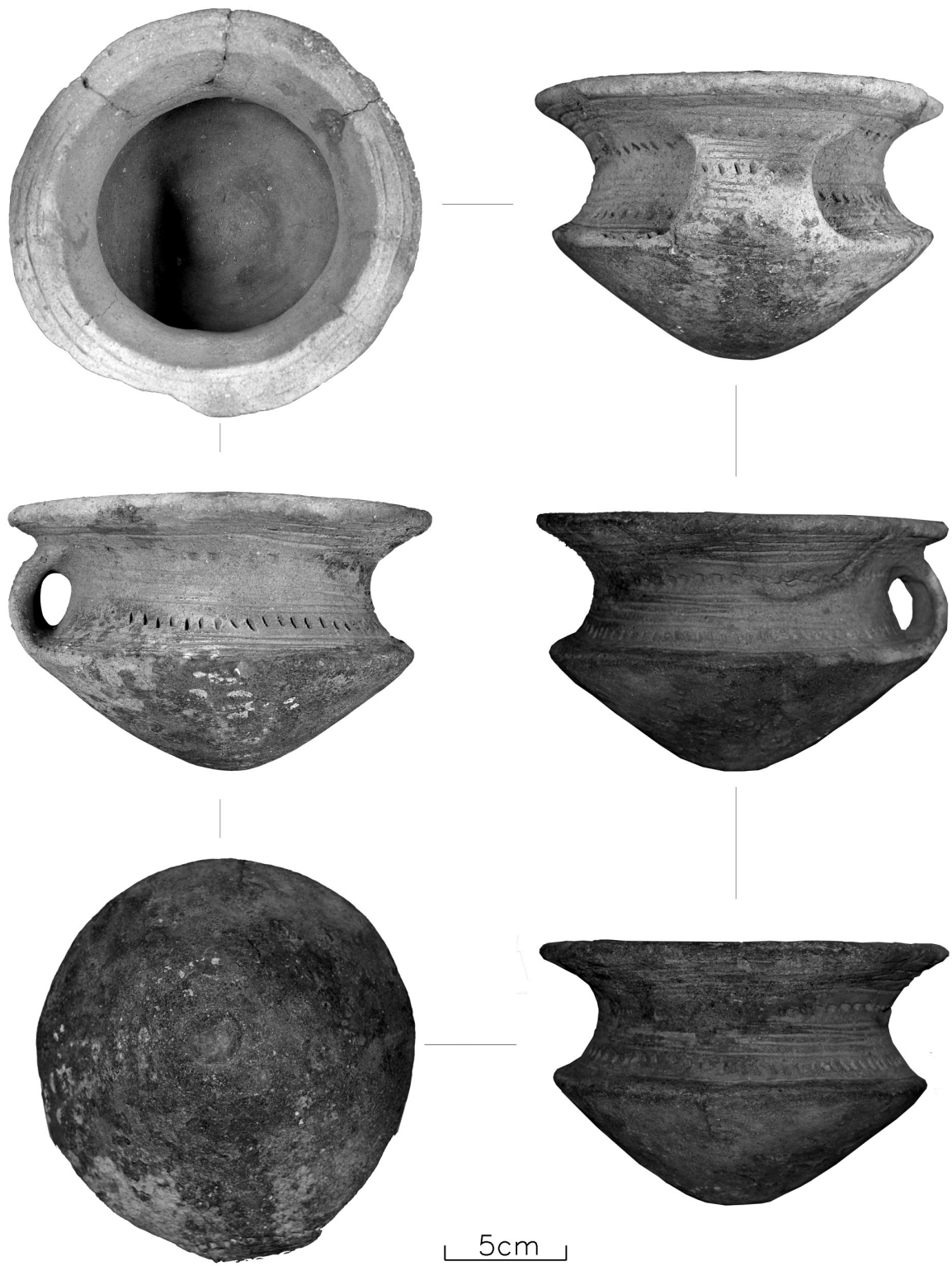

$5 \mathrm{~cm}$

Fig. 3. Fotografía del vaso desde distintas caras en perfil, desde la boca y el fondo (fotos MPPM). 


\section{Análisis de Paralelos del vaso carenado ¿Un Vaso único?}

Si observamos el vaso en su conjunto, podemos afirmar que no ha sido documentada otra vasija con las mismas características ni en la zona ni en regiones próximas. Así que, a través de un estudio formal, estudiando las diferentes partes de la pieza, trataremos de encontrar indicios que nos permitan encuadrar la pieza de manera aproximada en un contexto cronocultural relativo. Las características definidas y la asociación de paralelos nos ofrecerán la oportunidad de establecer una interpretación de la pieza. Nuestro trabajo partirá de la observación de patrones alfareros en dos niveles simultáneamente. El primer nivel es territorial comenzaremos estableciendo paralelos en Galicia, región en la que se localiza el vaso, para pasar a áreas más lejanas cuando sea pertinente. Al mismo tiempo, iremos considerando desde un punto de vista descriptivo las diferentes partes constitutivas del vaso para establecer, dentro de ellas, los rasgos más significativos para interpretarlo.

En lo que se refiere a Galicia (fig. 4), las carenas pueden encontrarse en vasijas desde el neolítico, pero en este momento, estas vasijas son raras; en este contexto, raro significa escaso pero también anómalo, pues sus características formales no responden al patrón cerámico del período, un ejemplo paradigmático de vaso carenado raro es el de Dombate ${ }^{8}$ o el del yacimiento de Requeán, que además posee un largo bordo horizontal ${ }^{9}$.

Las carenas son un rasgo más frecuente en los perfiles de los campaniformes gallegos, si bien, son carenas medias con un perfil anguloso más suave que el observado en Bexo, y los cuellos son más esbeltos pues predominan los vasos campaniformes frente a las cazuelas. Un buen ejemplo de recipiente carenado vinculado a la alfarería campaniforme es el de la cazuela lisa de Dombate ${ }^{10} \mathrm{o}$ algún campaniforme de A Lagoa o Zarra de Xoacín entre otros como ejemplos de carenas más bien bajas ${ }^{11}$ y la urna de Cameixa que es un ejemplo de recipien-

\footnotetext{
8 Serge Cassen, Christine Boujot, Salvador Domínguez Bella, Mikaël Guiavarc'h, Christophe Le Pennec, M. Pilar Prieto Martinez, Guirec Querré, Marie-Hélène Santrot y Emmanuelle Vigier, "Chapitre 16. Dépôts bretons, tumulus carnacéens et circulations à longue distance", en JADE. Grandes haches alpines du Néolithique européen Ve au IVe millènaires av. J.-C., Deuxieme partie: Les haches en jades; de l'Italie à l'Atlantique, Besançon, Les cahiers de la MSHE Ledoux, Tome 2, 2012, págs. 918-995.

9 L. Nonat, P. Vázquez Liz y M. P. Prieto Martínez, El Vaso de Largo... .

10 José María Bello Diéguez, Manuel Lestón Gómez y M. Pilar Prieto Martínez, "Dolmen de Dombate, entre lo funerario y lo doméstico", en María Pilar Prieto Martínez y Laure Salanova (coords.), Las Comunidades Campaniformes en Galicia. Cambios sociales en el III y II milenios BC en el NW de la Península Ibérica, Pontevedra, Diputación de Pontevedra, 2011, págs. 179-192.

${ }^{11}$ M. Pilar Prieto Martínez, "La alfarería de las comunidades campaniformes en Galicia: contextos, cronologías y estilo", en María Pilar Prieto Martínez y Laure Salanova (coords.), Las Comunidades Campaniformes en Galicia. Cambios sociales en el III y II milenios BC en el NW de la Península Ibérica, Pontevedra, Diputación de Pontevedra, 2011, págs. 334-361.
} 
te con una carena alta ${ }^{12}$. Las carenas de los vasos lisos de Partovia ${ }^{13}$ o Cova do Santo $^{14}$, en Ourense, muestran una misma tendencia semejante al del vaso de Bexo en los perfiles.

Si nos centramos en el borde, como decíamos anteriormente, el vaso de Bexo tiene un labio plano engrosado. Podemos encontrar un labio de morfología engrosada en una vasija de Penafita (Lugo), que fue interpretada como una imitación posible de $\mathrm{LBH}^{15}$, rasgo que apunta a una cronología avanzada en el II milenio $\mathrm{BC}$, aunque aquel vaso fue recuperado en prospección $\mathrm{y}$, por lo tanto, no tiene asociada una datación radiocarbónica ni un contexto definido. Asimismo podemos encontrar labios labios engrosados en el yacimiento de Cimalhas, lo que se denominan 'potes troncocónicos, com asa, decorados com mamilos e/ou incisôes variadas, ou sem decoraçâo', en concreto el recipiente PCSF/04-308/09 de la fosa $172^{16}$, este yacimiento presenta un área doméstica, otra de almacenamiento y otra funeraria y perdura a lo largo de la Edad del Bronce, especialmente Bronce Antiguo y Medio ${ }^{17}$.

La presencia de umbo es poco frecuente en las cerámicas prehistóricas gallegas. Esta presencia ha sido documentada hasta el momento sólo en cerámicas campaniformes, por ejemplo, un vaso de A Lagoa y otro de Devesa do $\mathrm{Rei}^{18}$, en las que el umbo es de mayor tamaño y menos resaltado en el perfil que el encontrado en el vaso de Bexo.

Si tratamos de buscar un recipiente que, en su perfil global, reúna el parecido más próximo al de Bexo podríamos señalar uno, no muy lejos del Ulla, hacia el sur en un yacimiento del Morrazo. Se trata del sitio de Os Torradoiros, en el que una

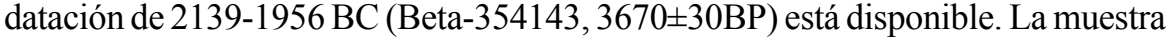
datada fue obtenida de los residuos carbonizados del interior de un recipiente liso,

\footnotetext{
${ }_{12}$ M. Pilar Prieto Martínez, Óscar Lantes SuÁrez y Antonio Martínez Cortizas, "Dos enterramientos de la Edad del Bronce en la provincia de Ourense", Revista Aquae Flaviae, 41 (2009), págs. 93-105.

13 José SuÁrez Otero. Pieza del mes de marzo de 2016. Vaso e cazola da Idade do Bronce, Partovia, $O$ Carballiño. Museo Arqueolóxico Provincial de Ourense, Xunta de Galicia, 2016.

14 José SuÁrez Otero, Pieza del mes de enero de 2014. Vaso da Idade do Bronce de Pardollán, Valdeorras. Museo Arqueolóxico Provincial de Ourense, Xunta de Galicia, 2014.

15 Pablo VÁzquez Liz, M. Pilar Prieto-Martínez y J. Francisco NúÑez Jato, "El pasado olvidado: El sitio del II y I milenio BC de Pena Fita (Adai, Lugo) en el contexto de las 'lonhouses' del NW peninsular", Gallaecia, 34 (2015), págs. 9-56.

${ }^{16}$ Pedro Brochado de Almeida y Francisco Fernández, "A escavaçâo arqueológica no Povoado das Cimalhas". Oppidum, 2 (2007), págs. 119-120.

17 Pedro Brochado de Almeida y Francisco Fernández, "O Povoado da Idade do Bronze da Cimalha". Oppidum, numero especial (2008), pág. 43.

${ }_{18}$ M. del Pilar Prieto-Martínez, "Devesa do Rei, contribución del estudio cerámico a la interpretación de la ocupación campaniforme”, en María Pilar Prieto Martínez y Laure Salanova (coords.), Las Comunidades Campaniformes en Galicia. Cambios sociales en el III y II milenios BC en el NW de la Península Ibérica, Pontevedra, Diputación de Pontevedra, 2011, págs. 163-169.
} 

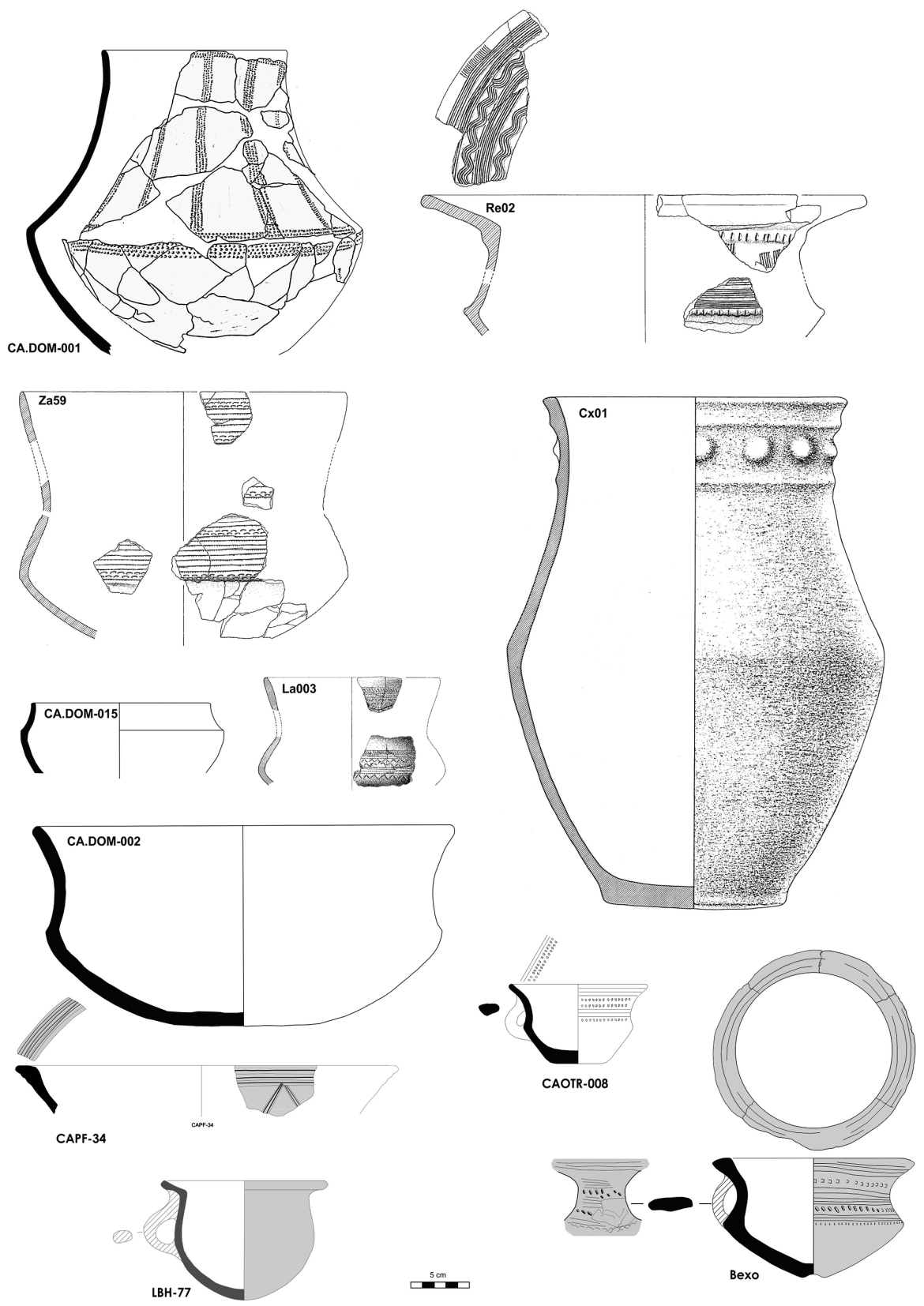
asociado a cerámicas con cordones horizontales y vasos campaniformes ${ }^{19}$. Uno de los vasos allí recuperados, el catalogado con el código CAOTR-008, es el que presenta mayores semejanzas al de Bexo, aunque es un vaso casi seis veces más pequeño, de $280 \mathrm{~cm}^{3}$, una capacidad semejante a la de los vasos de beber actuales, y del cual tampoco fue posible encontrar paralelos durante su investigación. El vaso de Os Torradoiros fue considerado como parte del paquete cerámico del momento de actividad probablemente doméstica allí datado, transición III-II milenio BC, frente al sitio funerario anejo de A Devesa de Abaixo, en el que claramente había habido actividad en diferentes momentos de la prehistoria hasta la Edad Media, siendo el más intenso entre el V y III milenio BC.

Además del perfil del recipiente, el asa del vaso carenado es un elemento significativo a valorar tipológicamente en un análisis de paralelos. Ésta es un elemento de prehensión poco frecuente en los recipientes de la prehistoria gallega, aunque están presentes en algunas vasijas desde el Neolítico Antiguo, su desarrollo cuantitativo y formal es más abundante a partir del s. XV BC aproximadamente. Los indicios de aumento de la frecuencia de las asas fueron

$\leftarrow$ Fig. 4. Dibujos de recipientes con carena de diferentes momentos de la prehistoria. CA.DOM-001 recipiente carenado de Dombate del Neolítico $\mathrm{Medio}^{20}$, Re02 recipiente con largo borde de Requeán del Neolítico Final ${ }^{21}$, La003 vaso campaniforme de A Lagoa, Za59 vaso campaniforme de Zarra de Xoacín, y CX01 urna de Cameixa del Bronce Inicial ${ }^{22}$, CA.DOM-002 y CA. DOM-015 recipientes carenados de Dombate del Neolítico Medio y quizás del Bronce Final, respectivamente ${ }^{23}$, CAOTR008 vaso carenado del yacimiento de Os Torradoiros asociado a material campaniforme ${ }^{24}$, LBH 77 de Marco de Camballón ${ }^{25}$, vaso carenado de Bexo, y recipiente CAPF-34 de Penafita, del Bronce Medio-Final ${ }^{26}$ (dibujos: AR, PPM y PVL).

\footnotetext{
19 Pablo VÁzquez Liz y M. del Pilar Prieto-Martínez, "El yacimiento de A Devesa de Abaixo (Pontevedra): Muerte y tradición en la Prehistoria Reciente del Noroeste de la península Ibérica", Cuadernos de Estudios Gallegos, 63, núm. 129 (2016), págs. 13-64.

20 S. Cassen, C. Boujot, S. Domínguez Bella, M. Guiavarc'h, C. Le Pennec, M. P. Prieto Martínez, G. Querré, M.-H. SAntrot y E. Vigier, “Chapitre 16. Dépôts,...”, págs. 918-995.

${ }^{21}$ M. Pilar Prieto-Martínez y Óscar Lantes SuÁrez, "Mobility in late Prehistory in Galicia: a preliminary interpretation from pottery", en Marie Besse and Jean Guilaine (eds.), Materials, productions, exchange network and their impact on the societies of neolithic Europe, Proceedings of the XVII UISPP World Congress (1-7 September 2014, Burgos, Spain), vol. 13/Session A25a, Oxford, Archaeopress Archaeology, 2017, págs. 51-67.

${ }^{22}$ M. P. Prieto-Martínez, O. Lantes SuÁrez, "Mobility in late...”, págs. 51-67.

23 J. M. Bello Diéguez, M. Lestón Gómez y M. P. Prieto Martínez, “Dolmen de Dombate...”, págs. 179-192.

24 P. Vázquez Liz y M. P. Prieto-Martínez, "El yacimiento de A Devesa...”, págs. 13-64.

${ }^{25}$ L. Nonat, P. Vázquez Liz y M. P. Prieto Martínez, El Vaso de Largo.... .

${ }^{26}$ L. Nonat, P. VÁzquez Liz y M. P. Prieto Martínez, El Vaso de Largo... .
} 
encontrados en el yacimiento de Fraga do Zorro ${ }^{27}$. Las asas también son más abundantes en el tipo cerámico de los LBH (largo bordos horizontales), tipo que se hace más frecuente a partir de la segunda mitad del II milenio BC, en los cuales se observa una morfología semejante a la observada en el vaso carenado de Bexo, un estrangulamiento en el centro del asa y ensanchamiento hacia las zonas de arranque, tanto superior como inferior.

Además de que la frecuencia de aparición en los vasos con asas sea mayor a medida que avanzamos en el segundo milenio $\mathrm{BC}$, podría haber una variación morfocronológica en las asas, pues las secciones suelen ser estrechas en los momentos más antiguos de la prehistoria reciente, con un perfil en cinta o circular, y a medida que avanza el segundo milenio BC, aumenta la anchura de la sección, como puede verse especialmente en el vaso de Bexo, pero también puede observarse en otros ejemplos numerosos como en los LBH o algunos vasos globulares (que en ocasiones aparecen en el mismo yacimiento en la región, caso de Marco de Camballón) (fig. 5). Otro ejemplo más de asas planas y anchas lo podemos encontrar en la vasija globular de Praia da Rola, datada en la segunda mitad del segundo milenio $\mathrm{BC}^{28}$. Sin embargo, este tipo de asas nos remiten a piezas mencionadas con anterioridad en este trabajo, las vasijas carenadas de Cova do Santo o Partovia, cuya cronología parece anterior, ya que, al menos los esqueletos datados en Cova do Santo $^{29}$, se enmarcan la primera mitad del II milenio BC siendo una referencia cronológica para dichas vasijas probablemente.

\footnotetext{
${ }_{27}$ M. Pilar Prieto-Martínez, y Dolores Gil Agra, "Fraga do Zorro: fosas y cacharros. Innovaciones en la alfarería de la necrópolis", en María Pilar Prieto Martínez y Laure Salanova (coords.), Las Comunidades Campaniformes en Galicia. Cambios sociales en el III y II milenios BC en el NW de la Península Ibérica, Pontevedra, Diputación de Pontevedra, 2011, págs. 139-147; M. Pilar Prieto-Martínez, Antonio Martínez Cortizas, Óscar Lantes SuÁrez y Dolores Gil Agra, "Estudio de la cerámica del yacimiento de fosas de Fraga do Zorro", Revista Aquae Flaviae, 41 (2009), págs. 107-121.

${ }^{28}$ La datación de la cista de Praia da Rola fue presentada en un poster titulado La cronología de los contextos funerarios no monumentales en el $\mathrm{NW}$ de la Península Ibérica, presentado en Iber-crono, Congreso de Cronometrías para la Historia de la Península Ibérica, Barcelona, 17-19 Octubre de 2016 por Pilar Prieto Martínez, Pablo Vázquez Liz. En la actualidad dichos autores están elaborando la publicación de este trabajo.

${ }^{29}$ La cronología de los esqueletos analizados en Cova do Santo, entre los ss. XIX y XVII BC, ofrecen una datación indirecta de gran utilidad para las vasijas allí encontradas, publicadas por Olalla LóPEz CosTAS, Gandula Müldner, Antonio Martínez Cortizas, "Diet and lifestyle in Bronze Age Northwest Spain: the collective burial of Cova do Santo”, Journal of Archaeological Science, 55 (2015), págs. 209-218.
} 


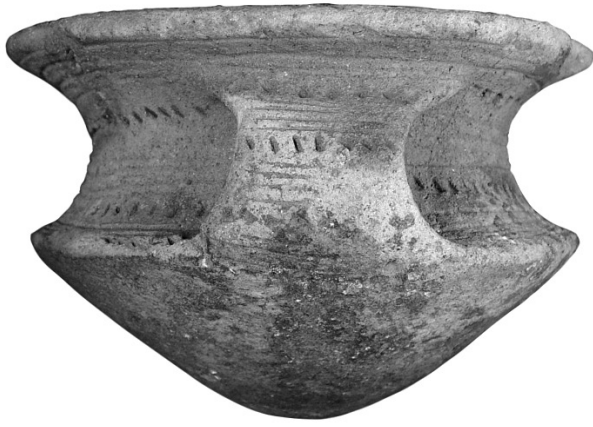

Bexo

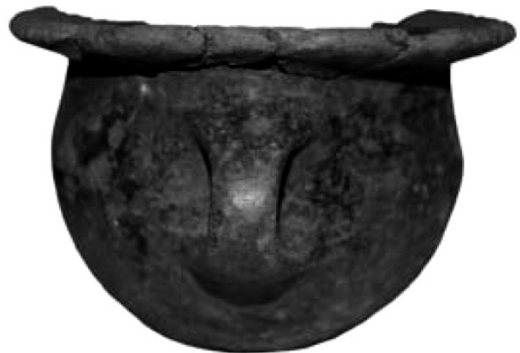

Marco de Camballón
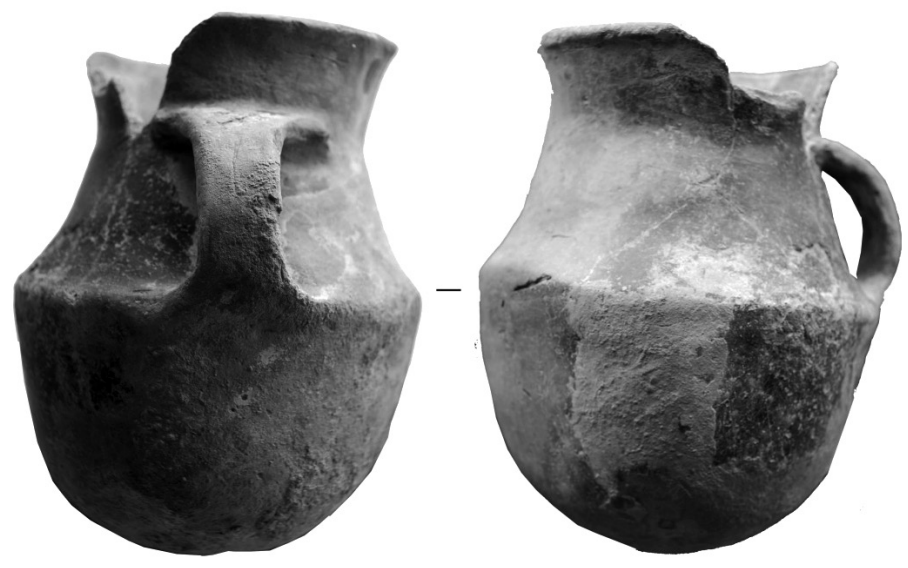

Pardollán

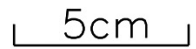

Fig. 5. Fotografía comparativa de los vasos de Bexo y LBH 77 de Marco de Camballón ${ }^{30}$ y Cova do Santo o Pardollán (fotos MPPM).

Si nos centramos como siguiente paso en la comparación en las pastas, los rasgos de éstas coinciden con las de las cerámicas del Bronce Medio y Final gallego ${ }^{31}$,

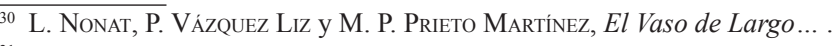

${ }^{31}$ Ver caracterización general en María Pilar Prieto-Martínez, "Ceramic style in Bronze Age societies in Galicia (NW Iberian Peninsula). Similarities and differences in patterns or formal regularity", en XIVth Congress of the U.I.S.P.P. (2-8 septiembre 2001, Liège). Section 11-l'Âge du Bronze en Europe et en Méditerranée/ The Bronze Age in Europe and the Mediterranean. General Sessions and Posters. Oxford, British Archaeological Reports, International Series, 1337, 2005b, págs. 99-107; se puede completar también con el trabajo de L. Nonat, P. Vázquez Liz y M. P. Prieto Martínez, El Vaso de Largo... .
} 
y en particular con las de los $\mathrm{LBH}^{32}$, son pastas medias predominantemente, pues su apariencia no es ni muy tosca ni muy fina, y por lo general algunos aspectos del tratamiento de la pasta (que no pudimos documentar en esta ocasión por no poder observar un corte de la pieza) indican un cierto control de calidad que no se resalta estéticamente en un acabado refinado.

En relación con los procesos deposicionales, se observan semejanzas a los documentados en algunos LBH en los que se encuentran superficies quemadas localizadas entre la base y el borde ${ }^{33}$ y que podrían responder a un mismo patrón de posicionamiento de la pieza al ser depositada en su contexto de uso.

Las técnicas decorativas observadas en el vaso, el acanalado (incisión fina realizada con un punzón de punta aguda) y la impresión, existen en todas las fases de la prehistoria, incluso su combinación en la misma vasija puede documentarse en el III milenio BC (p.e. en Requeán) o en vasos del II milenio BC, así que su uso o combinación no son específicos de una cronología o estilo cerámico particular. Si analizamos en detalle algunos aspectos de la decoración podemos destacar algunas cuestiones.

La incisión fina ha sido más bien documentada en yacimientos del Bronce Final en Galicia, como es el caso de algunas cerámicas del yacimiento de A Devesa do Rei asociadas a una datación del s. XIV-X BC, procedentes de un pequeño túmulo localizado en dicho yacimiento ${ }^{34}$.

La combinación de incisión fina e impresión se ha documentado en algún LBH, entre los que destaca por ejemplo el de Monte da Ola en Portugal ${ }^{35}$ que dispone de una datación tardía del s. XIII-X $\mathrm{BC}^{36}$. Otro paralelo que combina incisión e impresión es el ya citado vaso globular de Partovia, localizado en una cavidad granítica y cuya cronología relativa es encuadrada en la Edad del Bronce ${ }^{37}$, que combina bandas alternas de triángulos incisos, líneas horizontales impresas e incisas, decoración que se vuelve a repetir hasta llegar a la línea de carena.

\footnotetext{
32 L. Nonat, P. Vázquez Liz y M. P. Prieto Martínez, El Vaso de Largo... .

33 L. Nonat, P. Vázquez Liz y M. P. Prieto Martínez, El Vaso de Largo..., fig. 28.

34 Roberto Aboal Fernández, Xurxo Ayán Vila, Felipe Criado Boado, M. Pilar Prieto Martínez y Marta TABArÉs Domínguez, "Yacimientos sin estratigrafía: Devesa do Rei, ¿un sitio cultual de la Prehistoria Reciente y la Protohistoria de Galicia?”, Trabajos de Prehistoria, 62(2) (2005), págs. 165-180.

${ }^{35}$ L. Nonat, P. Vázquez Liz y M. P. Prieto Martínez, El Vaso de Largo ...; Laure Nonat, M. Pilar Prieto Martínez y Pablo VÁzquez Liz, "From the regional to the extraregional: Wide Horizontal Rim Vessels and stamping in the second half of the second millennium BC in the NW Iberian peninsula", en Fernando Coimbra, Davide Delfino, Valeriu Sîrbu y Cristian Schuster (eds), Late Prehistory and Protohistory: Bronze Age and Iron Age. Proceedings of the XVII UISPP World Congress (1-7 september 2014, Burgos, Spain), Oxford, Archaeopress Archaeology, 2016, págs. 127-143.

36 António Dinis y Ana M. S. Bettencourt, "Sondagens arqueológicas no Monte da Ola, Vila Fria, Viana do Castelo (Norte de Portugal)”, Portugália, 25 (2004), págs. 75-89.

37 J. SuÁrez Otero, Pieza del mes de marzo de 2016... .
} 

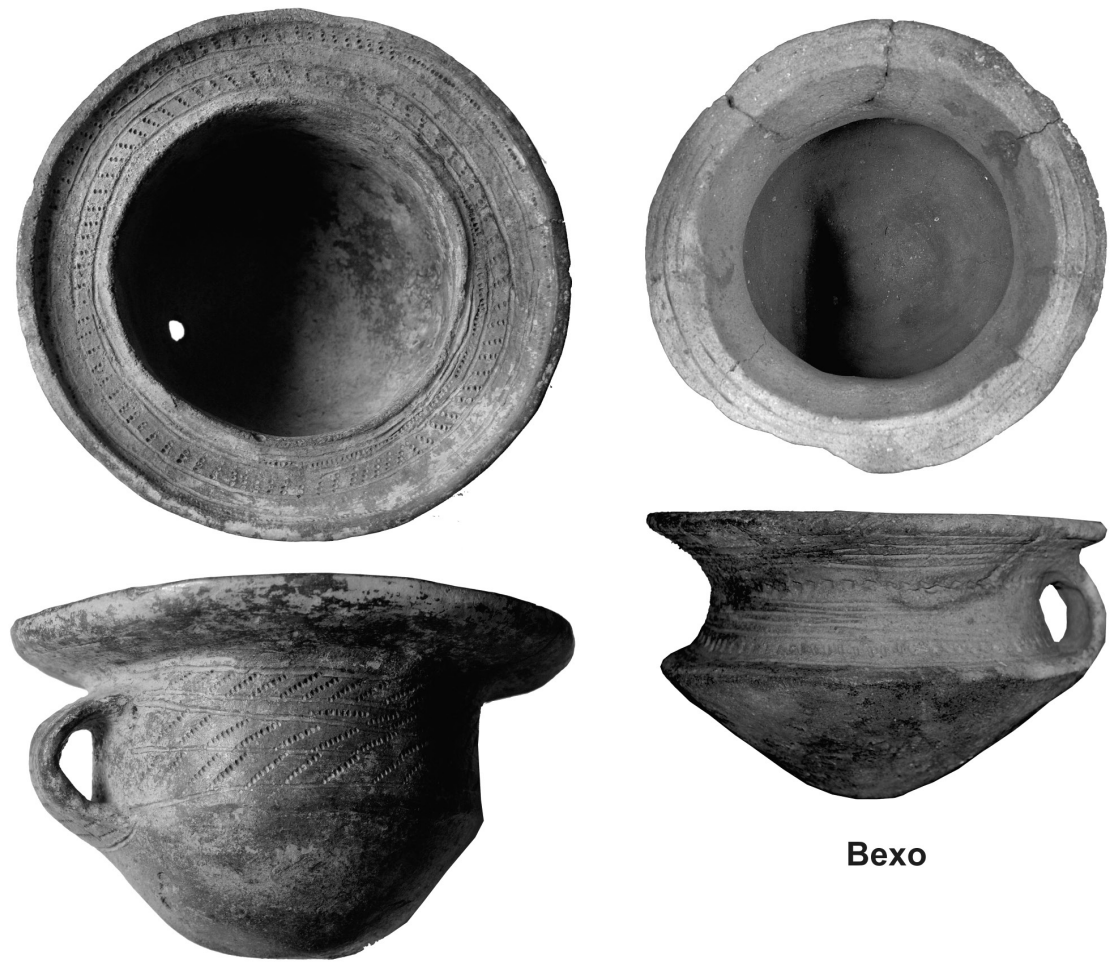

\section{Bexo}
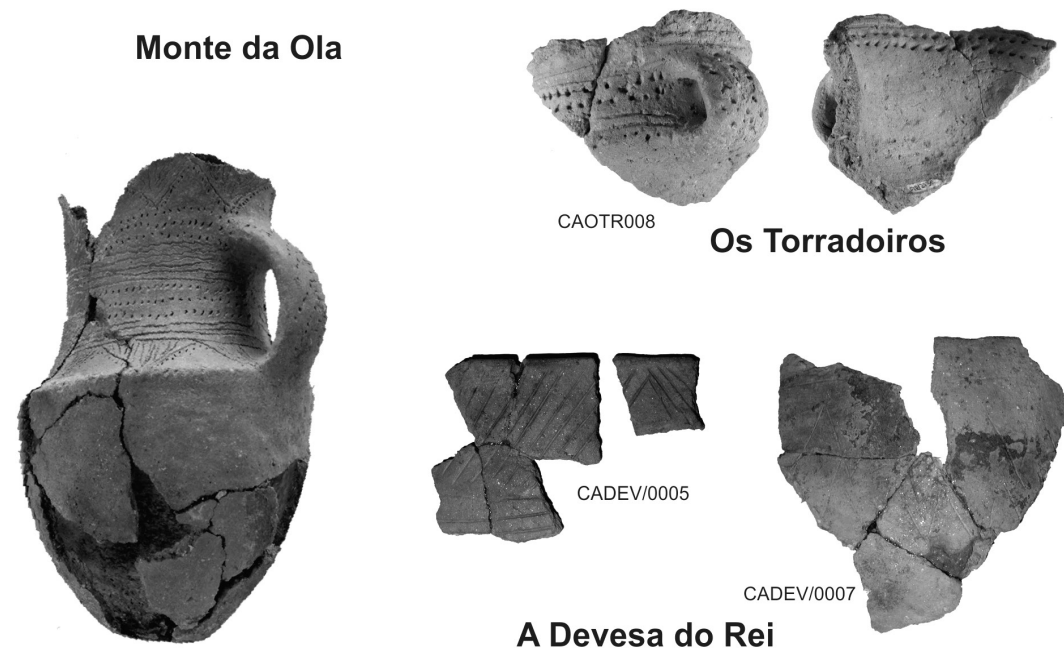

CAOTR008

Os Torradoiros

\section{Partovia}
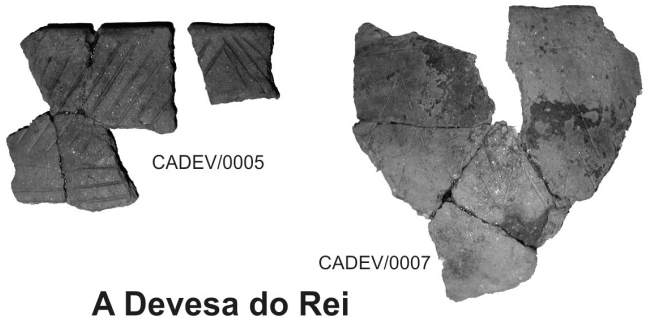

\section{A Devesa do Rei}

\section{$5 \mathrm{~cm}$}

Fig. Selección de la decoración de algunos recipientes gallegos de la segunda mitad del segundo milenio BC. 
Si, además, consideramos los diseños decorativos del vaso de Bexo, vemos que éstos son más propios de un mundo campaniforme y posterior, pues se organizan con líneas horizontales que refuerzan esa orientación en bandas horizontales. Frente a este tipo de patrón encontramos otro completamente diferente hecho con metopas, más típicas de las vasijas del Neolítico Final.

Por lo tanto, la organización de la decoración en el cuerpo del recipiente sigue más un patrón de las decoraciones de la Edad del Bronce, desde el campaniforme, que posee una tendencia a la reiteración de elementos que tienden a la horizontalidad, aunque cubriendo todo el recipiente, hasta avanzado el Bronce en donde esta tendencia a la horizontalidad se mantiene pero reduciendo el espacio decorativo a la mitad superior del recipiente, como en los vasos decorados de oro del tesoro de Caldas de Reyes, los LBH y quizás los vasos globulares, aunque estos últimos poseen decoración excepcionalmente (fig. 6).

Se puede observar que existen muchos rasgos comunes entre la vasija de Bexo y otras cerámicas en Galicia, sin embargo, es inevitable pensar en el interés que también tiene tratar de establecer paralelos más allá de nuestras fronteras. No sólo por la posibilidad de encontrar vasijas con mayor o menor parecido a la aquí presentada, sino también por poder confirmar la relación con otras regiones europeas. Varias regiones presentan ciertas tendencias en sus vasijas, no siempre cerámicas sino también en oro, que ofrecen ciertos rasgos en común con el vaso carenado de Bexo, y que pasamos a presentar.

En primer lugar, no se puede negar la existencia de algún tipo de contacto a mediados del II milenio BC entre yacimientos gallegos y yacimientos de la Cultura de Cogotas, pues ha sido constatada cerámica foránea en el islote de Guidoiro Areoso ${ }^{38}$, sito en la ría de Arousa, y próximo al hallazgo de Bexo. Por lo tanto, en el caso de Guidoiro parece clara la movilidad de cerámica, aunque no se sabe exactamente con qué zona se establecería el contacto. Este fenómeno de movilidad a largas distancias se ha constatado con el tesoro de Antas de Ulla, encontrado en el propio río Ulla hacia el noroeste del hallazgo de Bexo, y cuya materia prima parece proceder del sur de la Península Ibérica ${ }^{39}$.

Podemos alejarnos más en relación con el área geográfica a comparar. Desde el punto de vista formal, el vaso de Bexo guarda ciertos parecidos formales (decoración diseños y organización en el cuerpo del recipiente, forma carenada y

\footnotetext{
38 E. López-Romero, A. Güimil-Fariña, P. Mañana-Borrazás, C. Otero Vilariño, M. P. Prieto Martínez, J. M. Rey García y X. I. Vilaseco Vázquez, “Ocupación humana y...” págs. 353-371; M. P. Prieto-Martínez y O. Lantes SuÁrez, "Mobility in late...”, págs. 51-67.

39 Beatriz Comendador Rey, Jorge Millos y Paula Álvarez-Iglesias, "Provenance of the prehistoric silver set of Antas de Ulla, north-western Iberia, using lead stable isotope ratios", en Harald Meller, Roberto Risch y Ernst Pernicka (eds.), Metals of power-Early gold and silver. 6th Archaeological Conference of Central Germany (October 17-19, 2013, Halle, Saale), Halle, 2014, págs. 285-308.
} 
forma y localización del asa) con vasos metálicos que se registran en varias zonas de Europa, pero en particular con la cultura de Wessex, como por ejemplo, el vaso de Winterborne St. Martin ${ }^{40}$, el de Farway ${ }^{41}$ o el de Amesbury ${ }^{42}$. Aunque sin carena pero con un leve recuerdo decorativo, los dos vasos decorados del tesoro de Caldas de Reyes ofrecen un mismo patrón ${ }^{43}$. Asimismo, guarda semejanzas morfológicas con vasos del yacimiento del Bronce de Atalaya en Portuga ${ }^{44} \mathrm{O}$ lejanamente con las carenas que se registran en muchos recipientes argáricos. Sin embargo, los modelos cerámicos argáricos nada tienen que ver en cuanto a pastas o decoraciones con el vaso de Bexo. Asimismo, se pueden encontrar vasos carenados con asa en sitios franceses como el de la gruta sepulcral de Duffaits (La Rochette, Charente) ${ }^{45}$, donde se documentan decoraciones con impresiones de gran tamaño que provocan un efecto visual semejante al representado en el de Bexo.

Este ejercicio comparativo nos muestra simplemente que el vaso de Bexo responde a una tendencia morfológica generalizada, no sólo en cerámica sino también en piezas metálicas, en la Edad del Bronce de otras áreas europeas, y que, sin duda, a medida que conozcamos mejor el registro y más yacimientos, podremos documentarlo también en Galicia, como se está descubriendo en yacimientos recientemente publicados como Partovia o Cova do Santo en Ourense.

\section{INTERPRETACIÓN Y COMENTARIOS FINALES}

Nos encontramos con un vaso que, por su apariencia, es único en el registro gallego. No hemos podido encontrar otro recipiente semejante en Galicia ni en el noroeste Ibérico. Sin embargo, si se analizan en detalle sus características, se va vislumbrando un camino diferente, en el que la vasija encaja en un patrón propio de las cerámicas fabricadas en la Edad del Bronce postcampaniforme, probablemente asociado a la segunda mitad del segundo milenio BC (borde engrosado, asa de cinta ancha, carena muy pronunciada, decoración limitada a la mitad superior del cuerpo).

Sin duda, además del estudio formal y tipológico desarrollado en el presente trabajo, sería necesario realizar el análisis de su composición mineralógica y elemental para valorar al menos su origen local o foráneo. Asimismo, este tipo

\footnotetext{
${ }_{40}$ Hermann Müller-Karpe, Handbuch der Vorgeschichte. Vierter band Bronzezeit. Dritter Teilband Tafeln, München, C.H. Beck’sche Verlagbuchhandlug, 1980, tafel 475 A.2.

${ }^{41}$ H. MÜller-KARPE, Handbuch der Vorgeschichte..., tafel 476 P.

${ }^{42}$ H. Müller-Karpe, Handbuch der Vorgeschichte..., tafel 476 S.

${ }^{43}$ H. MüLler-Karpe, Handbuch der Vorgeschichte..., tafel 455.

${ }^{44}$ H. Müller-Karpe, Handbuch der Vorgeschichte..., tafel 451, E.2.

45 José Gomez de Soto, "La grotte sépulcrale des Duffaits (La Rochette, Charente)", Bulletin de la Société préhistorique française, 70 (1973), pág. 408.
} 
de analítica permitiría establecer una comparación con resultados de otras vasijas analizadas ya para la región y, al menos, verificar si existen semejanzas en los patrones de preparación de materias primas y otros procesos de fabricación de la alfarería del segundo milenio BC.

En relación con la cronología debemos ser cautelosos, aunque la búsqueda de más paralelos, sería extremadamente útil, no sería definitiva en la investigación. Partiendo de lo caracterizado, se observa que la mayor parte de los paralelos recuperados apuntan a un momento avanzado del II milenio BC, probablemente del Bronce Medio o Final, quizás relacionado con otros hallazgos metálicos mencionados en la introducción de este trabajo, o con vasos con decoraciones próximas como los encontrados en Cimalhas. Pero tampoco podemos descartar dos de los ejemplos más tempranos mencionados, la pieza de Os Torradoiros, con una cronología enmarcada en la transición entre el III y II milenio BC, y la cazuela de Cova do Santo con una datación de primera mitad del II milenio BC (en ambos casos las dataciones tiene una relación indirecta con las piezas pues no hay conexión estratigráfica entre las muestras datadas y las piezas mencionadas), que podrían apoyar también una posible mayor antigüedad para el vaso de Bexo.

Además de que el vaso esté inmerso en una tradición de origen local, no debemos abandonar otras opciones que pueden ser complementarias, y resultado de procesos sociales que todavía no podemos interpretar con precisión, como por ejemplo, que el vaso de Bexo pueda ser una imitación de LBH. Tampoco debemos descartar la movilidad del propio vaso, que pudiera haber sido traído de otra zona o del alfarero/a que lo haya fabricado, pues es un hecho demostrado para algún otro ejemplo en Galicia, aunque no es un fenómeno detectado en el registro arqueológico de manera muy frecuente todavía.

Lo que no tiene duda es que el vaso responde a un patrón generalizado en Europa en la época, y que éste se reproduce no sólo en vasijas de cerámica sino en vasijas hechas en otros materiales, incluidos los más preciosos como el oro, mostrando la inclusión de esta zona en un círculo de conexiones a gran escala.

A la espera de poder descubrir hallazgos contextualizados como el de Bexo, esperamos con este trabajo contribuir, al menos, a hacer pública una pieza única en la región, con el afán de que sea divulgada, y quizás reconocida por otros investigadores que puedan ayudarnos a ajustar más nuestras interpretaciones, así como a la espera de disponer quizás en el futuro con la posibilidad de poder contar con un registro más preciso y un contexto adecuadamente definido que permita datar la pieza en el futuro. 


\section{BIBLIOGRAFÍA}

Aboal Fernández, Roberto, Ayán Vila, Xurxo, Criado Boado, Felipe, Prieto Martínez, M. Pilar y Tabarés Domínguez, Marta, "Yacimientos sin estratigrafía: Devesa do Rei, ¿un sitio cultual de la Prehistoria Reciente y la Protohistoria de Galicia?", Trabajos de Prehistoria, 62(2) (2005), págs. 165-180.

Barbeito Pose, Víctor José, Fábregas Valcarce Ramón, Rodríguez Rellán, Carlos, Blanco Chao, Ramón, Costa-Casais, Manuela, Martín Seijo, María, Paz Camaño, Alexandre, Fariña Costa, Alfonso y Gorgoso López, Lino, "Ocupacións domésticas na serra do Barbanza: resultados preliminares”, Gallaecia, 34 (2015), págs. 125-158.

Bello Diéguez, Jose María, Lestón Gómez, Manuel y Prieto Martínez, M. Pilar, "Dolmen de Dombate, entre lo funerario y lo doméstico", en María Pilar Prieto Martínez y Laure Salanova (coords.), Las Comunidades Campaniformes en Galicia. Cambios sociales en el III y II milenios BC en el NW de la Península Ibérica, Pontevedra, Diputación de Pontevedra, 2011, págs. 179-192.

Brochado de Almeida, Pedro y Fernandez, Francisco, “A escavaçâo arqueológica no Povoado das Cimalhas”. Oppidum, 2 (2007), págs. 115-123.

Brochado de Almeida, Pedro y Fernandez, Francisco, "O Povoado da Idade do Bronze da Cimalha". Oppidum, numero especial (2008), págs. 29-44.

Cassen, Serge, Boujot, Christine, Dominguez Bella, Salvador, Guiavarc'h, Mikaël, Le Pennec, Christophe, Prieto Martinez, M. Pilar, Querré, Guirec, Santrot, Marie-Hélène y Vigier Emmanuelle, "Chapitre 16. Dépôts bretons, tumulus carnacéens et circulations à longue distance", en JADE. Grandes haches alpines du Néolithique européen Ve au IVe millènaires av. J.-C., Deuxieme partie: Les haches en jades; de l'Italie à l'Atlantique, Besançon, Les cahiers de la MSHE Ledoux, Tome 2, 2012, págs. 918-995.

Comendador Rey, Beatriz, Millos, Jorge y Álvarez-Iglesias, Paula, "Provenance of the prehistoric silver set of Antas de Ulla, north-western Iberia, using lead stable isotope ratios", en Harald Meller, Roberto Risch y Ernst Pernicka (eds.), Metals of power-Early gold and silver. 6th Archaeological Conference of Central Germany (October 17-19, 2013, Halle, Saale), Halle, 2014, págs. 285-308.

Dinis, A. y Bettencourt, Ana M. S., "Sondagens arqueológicas no Monte da Ola, Vila Fria, Viana do Castelo (Norte de Portugal)”, Portugália, 25 (2004), págs. 75-89.

Fernández Abella, David, "El río Ulla: primeras investigaciones en la ruta fluvial al corazón de Galicia a la luz de la convención de la UNESCO", en J. Cascalheira y C. Gonçalves (eds.), JIA 2011, IV Jornadas de Jovens em Investigação Arqueológica. Promontoria monográfica 16, vol. II, 2012, págs. 107-117.

Gómez de Soto, José, "La grotte sépulcrale des Duffaits (La Rochette, Charente) ”, Bulletin de la Société préhistorique française, 70 (1973), págs. 401-444.

González Insua, Félix, “Aproximación a la distribución espacial de sitios arqueológicos de la Prehistoria Reciente en la Ría de Arousa (Pontevedra)”, Gallaecia, 32 (2013), págs. 129-167.

Fábregas Valcarce, Ramón y Bradley, Richard, "El silencio de las fuentes: prácticas funerarias en la edad del Bronce del noroeste y su contexto europeo", Complutum, 6 (1995), págs. 153-146. 
López Costas, Olalla, Müldner, Gandula y Martínez Cortizas, Antonio, "Diet and lifestyle in Bronze Age Northwest Spain: the collective burial of Cova do Santo", Journal of Archaeological Science, 55 (2015), págs. 209-218. Doi: http://dx.doi.org/10.1016/j.jas.2015.01.009.

López-Romero, Elias, Güimil-Fariña, Alejandro, Mañana-Borrazás, Patricia, Otero Vilariño, Carlos, Prieto Martínez, M. Pilar, Rey García, Jose Manuel y Vilaseco Vázquez, Xosé Ignacio, "Ocupación humana y monumentalidad durante la Prehistoria Reciente en el islote de Guidoiro Areoso (Ría de Arousa, Pontevedra). Investigaciones en el marco de las dinámicas litorales atlánticas actuales”, Trabajos de Prehistoria, 72 (2) (2015), págs. 353-371. Doi: 10.3989/tp.2015.12159.

Meijide Cameselle, Gonzalo, "El concepto de las relaciones atlánticas en la Edad del Bronce del Noroeste", en Ladislao Castro Pérez y Susana Reboreda Murillo (coords.), Edad del Bronce, Xinzo de Limia, Excmo. Concello de Xinzo de Limia, 1994, págs. 197-231.

Müller-Karpe, Hermann, Handbuch der Vorgeschichte. Vierter band Bronzezeit. Dritter Teilband Tafeln, München, C.H. Beck'sche Verlagbuchhandlug, 1980.

Naveiro López, Juan L. El comercio antiguo en el NW peninsular, A Coruña, Edicións do Museo Arqueológico e Histórico, 1991.

Nonat, Laure, Vázquez Liz, Pablo y Prieto Martínez, M. Pilar, El Vaso de Largo Bordo Horizontal. Un trazador Cultural del Noroeste de la Península Ibérica en el II Milenio BC, Oxford, Archaeopress-BAR Internacional Series 2699, 2015.

Nonat, Laure, Prieto Martínez, M. Pilar y Vázquez Liz, Pablo, "From the regional to the extraregional: Wide Horizontal Rim Vessels and stamping in the second half of the second millennium BC in the NW Iberian peninsula", en Fernando Coimbra, Davide Delfino, Valeriu Sîrbu y Cristian Schuster (eds), Late Prehistory and Protohistory: Bronze Age and Iron Age. Proceedings of the XVII UISPP World Congress (1-7 september 2014, Burgos, Spain), Oxford, Archaeopress Archaeology, 2016, págs. 127-143.

Prieto Martínez, M. Pilar, "Ceramic style in Bronze Age societies in Galicia (NW Iberian Peninsula). Similarities and differences in patterns or formal regularity", en XIVth Congress of the U.I.S.P.P. (2-8 septiembre 2001, Liège). Section 11-l'Âge du Bronze en Europe et en Méditerranée/ The Bronze Age in Europe and the Mediterranean. General Sessions and Posters. Oxford, British Archaeological Reports, International Series, 1337, 2005, págs. 99-107.

Prieto Martínez, M. Pilar, "Devesa do Rei, contribución del estudio cerámico a la interpretación de la ocupación campaniforme", en María Pilar Prieto Martínez y Laure Salanova (coords.), Las Comunidades Campaniformes en Galicia. Cambios sociales en el III y II milenios BC en el NW de la Península Ibérica, Pontevedra, Diputación de Pontevedra, 2011, págs. 163-169.

Prieto Martínez, M. Pilar, "La alfarería de las comunidades campaniformes en Galicia: contextos, cronologías y estilo", en María Pilar Prieto Martínez y Laure Salanova (coords.), Las Comunidades Campaniformes en Galicia. Cambios sociales en el III y II milenios BC en el NW de la Península Ibérica, Pontevedra, Diputación de Pontevedra, 2011, págs. 334-361.

Prieto Martínez, M. Pilar y Gil Agra, Dolores, "Fraga do Zorro: fosas y cacharros. Innovaciones en la alfarería de la necrópolis", en María Pilar Prieto Martínez y Laure Salanova (coords.), Las Comunidades Campaniformes en Galicia. Cambios sociales en el III y II milenios BC en el NW de la Península Ibérica, Pontevedra, Diputación de Pontevedra, 2011, págs. 139-147. 
Prieto Martínez, M. Pilar y Lantes Suárez Oscar, "Mobility in late Prehistory in Galicia: a preliminary interpretation from pottery", en Marie Besse and Jean Guilaine (eds.), Materials, productions, exchange network and their impact on the societies of neolithic Europe, Proceedings of the XVII UISPP World Congress (1-7 September 2014, Burgos, Spain), vol. 13/Session A25a, Oxford, Archaeopress Archaeology, 2017, págs. 51-67.

Prieto Martínez, M. Pilar, Lantes Suárez, Óscar y Martínez Cortizas, Antonio, "Dos enterramientos de la Edad del Bronce en la provincia de Ourense", Revista Aquae Flaviae, 41 (2009), págs. 93-105.

Prieto Martínez, M. Pilar, Martínez Cortizas, Antonio, Lantes Suárez, Óscar y Gil Agra, Dolores, "Estudio de la cerámica del yacimiento de fosas de Fraga do Zorro", Revista Aquae Flaviae, 41 (2009), págs. 107-121.

Suárez Otero, José, Pieza del mes de enero de 2014. Vaso da Idade do Bronce de Pardollán, Valdeorras. Museo Arqueolóxico Provincial de Ourense, Xunta de Galicia, 2014.

Suárez Otero, José, Pieza del mes de marzo de 2016. Vaso e cazola da Idade do Bronce, Partovia, O Carballiño. Museo Arqueolóxico Provincial de Ourense, Xunta de Galicia, 2016.

Vázquez Liz, Pablo, Prieto-Martínez M. Pilar y Núñez Jato, J. Francisco, "El pasado olvidado: El sitio del II y I milenio BC de Pena Fita (Adai, Lugo) en el contexto de las 'lonhouses' del NW peninsular", Gallaecia, 34 (2015), págs. 9-56.

Vázquez Liz, Pablo y Prieto Martínez, M. Pilar, "El yacimiento de A Devesa de Abaixo (Pontevedra): Muerte y tradición en la Prehistoria Reciente del Noroeste de la península Ibérica", Cuadernos de Estudios Gallegos, 63, núm. 129 (2016), págs. 13-64. DOI: 10.3989/ ceg.2016.129.01. 